\title{
La incorporació de les aportacions de les científiques en els materials didàctics
}

\author{
Núria Solsona Pairó \\ IES Josep Pla, Barcelona
}

Diferents materials didàctics d'ESO recullen les aportacions d'algunes científiques al llarg de la història. La utilització didàctica de les receptes de Marie Meurdrac, del segle XVII serveix de referència perquè l'alumnat escrigui les seves receptes en treballar la introducció a la química.

\section{Introducció}

El professorat de Ciències Experimentals ens hem endinsat alguna vegada en un llibre d'història de la ciència i potser fins i tot en un llibre que parlava de les aportacions de les científiques a la història del coneixement. Creiem interessant introduir aquestes aportacions en els materials didàctics de l'aula.

\section{Algunes figures científiques en els materials didàctics}

La introducció d'algunes científiques i les seves aportacions en l'estudi dels materials i les seves propietats es pot fer quan es parla d'altres classificacions dels sòlids. Una lectura possible seria aquesta:

"L'any 1922, les propietats d'uns nous materials, els primers plàstics, van ser explicades per Herman Staudinger i la seva dona, la doctora Marga Staudinger, treballant en estreta col-laboració. En aqueIla època, principis del segle $X X$, encara era difícil per a una dona d'anar a la Universitat. Hi havia poques dones científiques. Pel que se sap de les seves investigacions, les millors idees sobre els polímers van ser d'ella. De totes maneres Herman Staudinger va rebre el premi Nobel el 1953." (Izquierdo i al, 2003).

Quan s'estudia el canvi químic, en parlar de substàncies simples i compostes es pot introduir la primera figura de l'alquímia, Maria la Jueva, amb un dibuix que reprodueix els alambins dissenyats per ella: el tribikos i el kerotakis (fig. 1). Maria la
Jueva va viure a Alexandria, Egipte, probablement el segle III de la nostra era (Solsona, 2003).

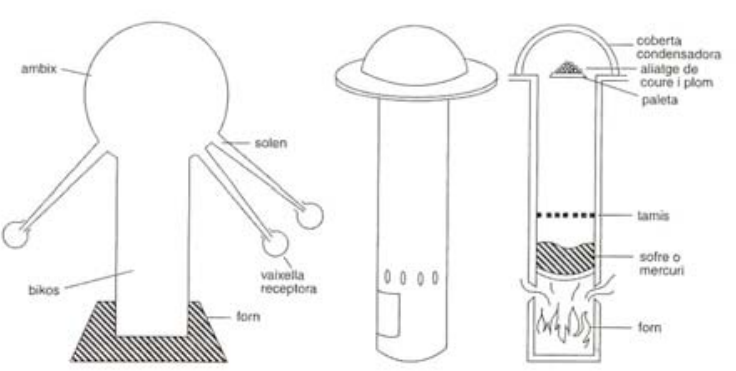

Figura 1. Els alambins de Maria la Jueva: tribikos (esquerre) i kerotakis (dreta: vista exterior i secció).

Quan treballem l'energia cal tenir present que moltes dones van ser pioneres en la ciència nuclear (Álvarez i al., 2003). Al tractar el descobriment de la radioactivitat, podem recuperar Marie Curie (el seu nom de soltera era Marja Skolodska), que va néixer a Polònia l'any 1867 i va morir el 1934. Es va llicenciar en ciències físiques i en ciències matemàtiques. Va començar a fer recerca treballant amb els "raigs de Becquerel". Va començar a analitzar un gran nombre d'elements i descobrí que l'urani no era l'únic element radioactiu. Va conèixer Pierre Curie, amb qui es casà el 1895, treballant junts a partir de llavors. L'any 1903 Becquerel i els Curie van rebre conjuntament el premi Nobel de Física pel seu descobriment de la radioactivitat. Els Curie també van rebre la medalla "Davy" i al 1911 Marie encara va rebre el premi Nobel de Química pel descobriment del poloni i del radi. 
Marie Curie va definir la radioactivitat com: "un procés atòmic que no està afectat ni per l'estat físic ni per la combinació química dels àtoms radioactius amb altres elements. Aquest procés... transforma l'àtom! I aquesta transformació es produeix de manera aleatòria (no es pot saber quins dels àtoms es transformaran), a una velocitat diferent per a cada un dels elements radioactius, que disminueix exponencialment el nombre d'àtoms encara no transmutats". A continuació es recorden les dades que disposava Marie Curie per arribar a aquesta conclusió tan revolucionària, les conseqüències de la radioactivitat en els organismes i la mort de Marie Curie per leucèmia, probablement a causa de les seves investigacions.

En materials didàctics com les Guias Praxis para el profesorado de ESO. Ciencias de la Naturaleza (Solsona i Sanmartí, 1998), en El cambio químico: pequeñas biografías interesantes parlàvem de Maria la Jueva i d'Elizabeth Fulhame.

\section{Maria la J ueva}

L'origen de la tradició alquímica precursora de la química actual, es pot situar a Alexandria, en els primers segles de la nostra era. En coincidència amb les idees pròpies de l'antic Egipte, l'alquímia tenia un gran interès en els metalls i en els temes místics.

Maria la profetessa és una de les primeres figures conegudes de l'alquímia. No s'han conservat dades d'on ni quan va viure però probablement va ser al segle III. No s'han conservat els seus textos que segurament vas ser destruits en el segon incendi de la biblioteca d'Alexandria, provocat per Teodosi I, l'any 389 de la nostra era, però fou citada per tota la tradició alquimista. Maria mereix la consideració de fundadora de l'alquímia occidental. Fou l'inventora del bany maria, que porta el seu nom en totes les llengües europees, i de diferents instruments, com alambins i tècniques de laboratori que encara avui s'utilitzen.

A diferència d'alguns alquimistes que únicament van realitzar treball empíric, la part més interessant de les ensenyances de Maria radica en les seves doctrines sobre la naturalesa. Estan enunciades en forma d'axiomes i són la base dels procediments que descriu i recomana. A partir dels escrits del seu deixeble Zòsim es creu que Maria, d'acord amb les doctrines acceptades a Alexandria, pensava que tots els cossos i substàncies que es troben a la naturalesa en són bàsicament un de sol. (Solsona i Sanmartí, 1998).

\section{Elizabeth Fulhame}

D'Elisabet Fulhame es conserva el llibre que va publicar el 1794,"Assaig sobre la combustió". Pels comentaris que inclou en el llibre, fou una científica anglesa de família culta que podia discutir amb els científics de l'època i estava interessada en les investigacions del moment. El seu llibre es va publicar i va tenir una bona acollida entre els químics contemporanis. Fou elegida membre honorari de la Societat Química de Filadèlfia. El llibre es va tornar a imprimir el 1810.

El seu pròposit inicial era buscar aplicacions pràctiques pels seus experiments. Però Fulhame no sols va participar en els aspectes pràctics o experimentals de la ciència, sinó que va desenvolupar també explicacions teòriques elaborant la seva pròpia teoria de la combustió. Fulhame va rebutjar en part la teoria de la combustió de Lavoisier i no va acceptar la seva nomenclatura. Fulhame tampoc acceptava la teoria del flogist, i va definir l'oxigenació com la unió de l'oxigen amb el combustible, i va suposar que en qualsevol combustió hi ha descomposició de l'aigua. Per tant, un cos s'oxigena amb l'oxigen de l'aigua, al mateix temps que l'altre recupera l'estat de combustible amb l'hidrogen de l'aigua. (Solsona i Sanmartí, 1998).

\section{Les receptes de Marie Meurdrac}

Marie Meurdrac (1999) i el seu llibre "La Chymie charitable et facile en faveur des dames" (1666) (fig. 2), són un bon exemple de les reflexions alquimistes del segle XVII. Sempre m'han cridat l'atenció les seves receptes.

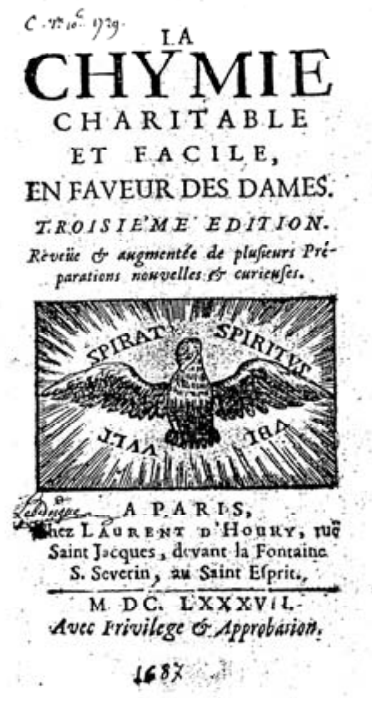

Figura 2. Portada del llibre de Marie Meurdrac.

A França, en aquella època encara cremaven les dones sàvies i els medicaments no estaven fàcilment a l'abast de l'alta aristocràcia, tot i que la 
salut era una de les poques preocupacions que tenien. Lluís XIV va comprar "un remei miraculós a base de química" a un metge anglès. Sembla que la composició del remei era secreta i el Rei la va fer pública perquè tothom la pogués tenir, però calia saber preparar-la. Per la febre, es donaven "dos vasos de canyafístula", es prenia aigua de cireres, i era habitual fer purgues i sagnies, fins i tot després del part. Per la ràbia de la mossegada d'un gos es posava aigua de mar.

El llibre de Meurdrac va més enllà d'un tractat de química terapèutica, i té una diferència respecte als tractats contemporanis i és que parla de les composicions per a l'embelliment de la cara, dels cosmètics. Meurdrac es dirigeix especialment a les dones en la sisena part del llibre, "Les composicions para la bellesa facial", tal com ja havien fet altres autores. Els diu que podran trobar "totes aquelles coses que conserven i augmenten la bellesa". En la introducció afirma: "He afegit aquesta part al meu Llibre en favor de les Dames, per a advertirles d'un nombre infinit d'accidents que succeeixen posant-se coses a la cara, de les quals no se sap la seva composició". Posa èmfasi en dir: "Especialment aviso les Dames, perquè posin en les seves composicions per a la cara, la menor quantitat de Càmfora que puguin; ja que espatlla i fa mal bé les dents, i causa moltes congestions“. D'algunes substàncies àmpliament utilitzades per a blanquejar la pell escriu: "Per al mercuri, el sublimat (clorur de mercuri(II)), i l'estany de gel (bismut), jo aconsello no utilitzar-los gens: a més de destruir la bellesa facial quan s'usen durant llargs períodes, produeixen malalties perilloses que de vegades són incurables. Per aquest motiu, les dones hi han d'anar en compte [en l'ús]. Dono a més una quantitat de secrets i d'operacions per a l'embelliment, tant per als cabells, les dents i les mans, com per a conservar els guants, els mocadors i les toques de dia i de nit, i fer els folres de la màscara. Dono també el mètode per preparar tisanes per a engreixar, dormir i conservar la grassor".

En el primer capítol "De la sal" se situa respecte als principis espagírics i diu: "La química estudia els cossos mixtos divisibles i resolubles sobre els que ella treballa, per extreure'n els tres principis, que són sal, sofre i mercuri. Primerament parlarem de la sal com el pare de la generació, ja que sembla que és el que contribueix més a la producció... La sal fixa és aquella que esdevé visible per l'art... La sal nitre es troba al mig entre la fixa $i$ l'amoníac... L'amoníac és aquell que passa amb l'esperit i l'aigua en les destil.lacions"

En el capítol VI, "Els pintallavis" proposa la recepta "Per fer el carmí". En el capítol XI, "Les pastes, aigües i pomades per a les mans" dóna una recepta per a preparar "Pasta per a les mans": En el capítol XIV, "Les tisanes", proposa "Una altra tisana que engreixa i fa dormir": "Preneu sèmola de civada, y farina de civada, de cada una, una lliura; sis pomes reinetes tallades en rodanxes; poseu-ho tot en un vas nou de terra esmaltat, amb deu pintes d'aigua; feu bullir fins que hagi disminuït a la meitat. Després passeu-ho per una roba i poseu-hi sucre a discreció. S'ha de beure de bon matí, tres hores després de dinar, i a la nit a l'hora de dormir, cada vegada un gran vas. Aquesta tisana, a més de fer dormir, engreixa, humiteja i refresca. És bona per a les persones grans, i per als joves."

De les setanta-tres receptes incloses en la sisena part del seu tractat, destacaré en el capítol XIV, "Per a les dents" una recepta per a preparar "Aigua per a blanquejar les dents i per a fortificar les genives": "Prendre sal gemma, alum de roca (sulfat doble d'alumini i potassi parcialment deshidratat), sofre de canya de cada un deu onzes, bòrax una unça, perles i corral picats, de cada un una mitja unça, vinagre blanc destil.lat quatre unces: poseu-ho tot en una retorta i ho feu digerir una nit sobre cendres calentes. Després destil.leu-ho al foc de sorra, enceneu el foc fins al final. S'han de rentar les dents amb aquesta aigua amb una petita tela: blanqueja i fortifica les genives i cura les úlceres que surten a la boca".

\section{La introducció de les receptes en una seqüència didàctica}

Utilitzar les receptes de Marie Meurdrac és una manera de presentar a la classe alguns dels temes de l'alquímia i un exemple d'autoria femenina en el segle XVII. No cal fer gaires comentaris entorn a l'èxit que té a quart d'ESO la lectura de la introducció a la sisena part del llibre de Marie Meurdrac, adreçat a les dones. Avui dia, moltes noies i nois tenen el seu ideal particular de bellesa i d'estètica, ben diferent de l'ideal del segle XVII i n'hi ha que hi dediquen força temps i diners. A més, la lectura d'algunes receptes de Marie Meurdrac revalora una tipologia textual que és molt apropiada per l'alumnat d'ESO, ja que permet identificar clarament el procediment seguit en un experiment i iniciar-los en l'escriptura de textos científics experimentals.

Un exemple serien les receptes escrites a partir de les experiències culinàries de preparació de col-loides, fetes en la cuina-laboratori de l'Institut (Solsona i altres, 2005). La recepta per fer "croissants amb xocolata", del grup de la Laura és:

“1. Agafem els crusanets i els posem en una safata folrada de paper de plata. Quan el forn ja està calent, desprès de posar a $250^{\circ} \mathrm{C}$ el gratinador, posem la safata dins del forn i esperem 10 minuts.

2. Per l'altra banda en un pot posem a bullir llet al foc i hi tirem la xocolata en pols. Anem remenant fins que s'espesseixi la xocolata. 
3. Un cop passats els 10 minuts, treure els crusanets del forn (si estan torradets).

4. Cal presentar els aliments ben presentats."

Un altre grup ha preparat crema catalana, un col-loide seguint la recepta de la mare de la Neus i diu que han utilitzat el següent material: "100 g de sucre, 6 ous, $1 \mathrm{~L}$ de llet, $50 \mathrm{~g}$ de maizena, canyella i pell de llimona". La recepta diu: "Hem seguit les instruccions de la mare de la Neus. Es bat el rovell de l'ou amb sucre. Es dissol la maizena amb una mica de llet. Es posa la llet en un bol amb la pell de llimona i la canyella. Se li afegeix l'ou amb sucre i la maizena i es mescla. Es posa al foc i es va batent tot a foc lent, fins que s'espesseixi."

En la preparació del pa de pessic, el canvi químic paradigmàtic, la Marta escriu la seva recepta: "Per fer un pa de pessic farcit de xocolata, necessitem primerament quatre ous, els quals hem de batre. Posem els quatre ous batuts en una base on afegim quatre cullerades de sucre, quatre de farina i una bossa de llevat. A continuació anem remenant la barreja, i afegim $50 \mathrm{~g}$ de mantega que hem fos anteriorment. Quan ja tenim tots els ingredients ho barregem tot fins que quedi homogeni a la vista, és a dir que no puguem distingir els ingredients. En acabar, agafem el motlle i el farcim de mantega per tota la base per evitar que quedi enganxat quan el posem al forn. Aboquem la barreja en el motlle i el posem al forn a $220^{\circ} \mathrm{C}$ durant uns 25 minuts. Hem d'anar mirant si el pa de pessic puja durant aquest temps i quan ja estigui en el seu punt el traiem, el deixem refredar i afegim xocolata per sobre. Llavors, ja es pot menjar!"

Escriure la recepta és un primer estadi per pensar, parlar i escriure sobre l'experiment, és a dir una primera via per convertir les idees en paraules $i$ elaborar una explicació del fenomen. Les receptes escrites per l'alumnat són una primera forma d'ordenar i reelaborar els coneixements associats a l'experiment escolar. I els termes utilitzats en la recepta permeten saber si s'està aprenent a elaborar explicacions científiques. Per exemple, no és el mateix escriure "posar la xocolata en la llet" o "dissoldre la xocolata en la llet" com ho fa el grup de la Neus. He observat que l'alumnat que escriu: "fins que es formi el col-loide", enlloc de "remenar fins que s'espesseixi la xocolata", és el que després acostuma a tenir menys dificultats en la construcció del model de canvi químic.

\section{Consideracions finals}

La majoria de les científiques van ser dones $a m b$ autoritat en la seva època. Una autoritat que no van entendre com a poder, sinó com a mediació amb altres persones que volien aprendre.

Etimològicament autoritat ve del llatí augere que significa capacitat per fer créixer. La nostra voluntat seria que les científiques que hi ha hagut al llarg de la història fessin de mediadores amb l'alumnat actual, especialment amb aquelles noies que no s'interessen per les ciències.

Treballar amb els textos i les biografies de les dones científiques és important per donar a les noies models de referència que els permetin identificar-se amb l'activitat científica escolar i animar-les a fer estudis universitaris de ciències.

D'altra banda, recuperar les científiques que han fet aportacions al llarg de la història, i la seva manera diferent de treballar, en ocasions permet reconstruir la història de la ciència, tot i destacant les contribucions de les dones. Reconstruir la participació de les dones en la història de la ciència significa comprendre i aprendre de les experiències, dels pensaments i sabers de les dones.

\section{Bibliografia}

Álvarez, Mari i al. (2003). Las científicas y su historia en el aula. Madrid, Síntesis.

Meurdrac, Marie (1999). La Chymie charitable et facile en faveur des Dames (1666). Paris, CNRS Editions.

Solsona, Núria (1997). Mujeres científicas de todos los tiempos. Madrid, Talasa.

Solsona, Núria; Sanmartí, Neus (1998). El cambio químico. Guias Praxis para el profesorado de ESO. Ciencias de la Naturaleza. Barcelona, Praxis.

Solsona, N. (2003). El saber científico de las mujeres. Madrid, Talasa.

Izquierdo, Mercè i al. (2003). La diversitat i la unitat dels materials. Sistemes químics: de què estan fets els materials? Barcelona, Ciència Activa. 